\title{
Curriculum of Visual Arts on Basic Education: Classrooms' Everyday Life and Teachers' Formation
}

\author{
By Aldo Victorio Filho* \\ Inês Barbosa de Oliveira ${ }^{\dagger}$
}

\begin{abstract}
We aim to problematize the curricular proposals that surround the participation of Visual Arts on the Basic Education teaching process. In order to accomplish this goal, we appeal to the discussion of some guidelines which are currently in force for Arts teaching at elementary school, as well as the aspects of their theoretical anchorage. The purpose of Arts education on Basic School might be considered in line with a Project of Human Formation still guided by the hegemonic cultural pattern. Both the realization and knowledge of aesthetic productions would lead to world reading and representation. However, we consider the 'exploitation of the imagistic universe' recommended by the Brazilian National Curricular Parameters will only have significant consequences beyond Party conductions of Education if the processes which are demanded are adequately contemplated and mediated on the concreteness of the classroom's everyday life, where each parameter designed as dominant wrecks. Taking into consideration the notion of difference, this reflection about the curricular postulates of Arts tries to elucidate some aspects such as the desired 'development of attention, memorization and gesture capacities as well as other body abilities' seeking the conceptual enlargement of these capacities. We show our theoretical adventure that intends to contribute for a curricular accomplishment compatible with the present moment. The research about the genealogy of intimate Education utopia, considering the World Images and Imagistic World to study curriculum, visual culture and teacher formation are the main discussions purposed in this paper. We understand that the participation of Arts teaching on a successful school formation in tune with present time depends on the acute conceptual limits imposed to the first one and to the recognition of overflows that its epistemic field and peculiar practices have imposed to curricular gates of the second one: the contemporary formal education.
\end{abstract}

${ }^{*}$ Professor, State University of Rio de Janeiro (UERJ), Brazil.

†Professor, State University of Rio de Janeiro (UERJ), Brazil. 


\section{Introduction}

We aim to problematize the curricular proposals that surround - with certain intensity - the participation of Visual Arts on the Basic Education teaching process. In order to accomplish this goal, we appeal to the discussion of some guidelines which are currently in force for Arts teaching at elementary school, as well as the aspects of their theoretical anchorage.

The purpose of Arts education on Basic School, in a panoramic sight, might be considered in line with a Project of Human Formation still guided by the hegemonic cultural pattern. Both the realization and knowledge of aesthetic productions - being considered artistic or not - would lead to world reading and representation. However, the 'exploitation of the imagistic universe' recommended by the Brazilian National Curricular Parameters will only have significant consequences beyond Party conductions of Education if the processes which are demanded are adequately contemplated and mediated on the concreteness of the classroom quotidian, where each parameter designed as dominant wrecks. Reading and producing a fairer and more welcoming world depend on the paving of a specific, stimulating, challenging route, with favorable conditions for learners, implying on continuous consideration of cultural plots and aspects that differentiate them on learning collective, spaces and times. Each student keeps a unique net of references, affections and crossings from which is possible for him/her to connect with his/her school micro-collectives, where part of it makes contrast and most of it reframes on the effervescence of those environments, as the collective of each class is singular and self shaped at the mercy of connections among the 'self poiesis' of its subjects inside their interactions.

Taking into consideration the fundamental notion of difference, the reflection about the curricular postulates of Arts must try to elucidate some aspects such as the desired 'development of attention, memorization and gesture capacities as well as other body abilities' seeking the conceptual enlargement of these capacities considering that the supposed lack of attention just disguises the selection of objects which are privileged by the eye which is desired but escapes from the official curricular scenery. The entrance for a curricular (re)theorization that will elucidate the school scenery far beyond its old stigmas faces the indifferent glances to school activities. The search for understanding these glances will question the pedagogical sedimentations as well as the distance from the imagistic productions of the children and youth visual cultures and the meaning creations that arise there. Attention, memory and body abilities, on the other hand, would depend on creative and copyright actions of students and teachers in other curricular policies, in which developing the 'student's attention' would imply on the reformulation of the school attention, of the postulates which guide it and finally, on the effective tuning of the teacher with the current knowledge that escape from the subject organization, still in force on the official curriculum.

We observe that the desired aesthetics elaborations, which are irreducible to Arts system, are nothing but world apprehensions and reframes, so the 
contribution of Arts to Education would not be limited to the investment on the word, in other words, to reduction of what is substantially collective and individual aesthetic experience to discourse, convening just a totalizing rationality. The educational processes, almost always agreed on the word, no longer prescind the strong aesthetic dimension of the imagistic flows that reach everyone and cross the creation of collective imaginary. If the sensory material and the word are indispensable for concept formation, on the other hand, Art and any knowledge that has creation and aesthetic experience as elements require the word quarantine in favor of gesture, color, sound. Representing and observing the world, as well as experimenting its fruition and cognitive possibilities, it will only succeed if the efforts are conducted by the comprehension of lives from the views students and teachers both have about the world: views which are not stable, but are always procedural, favoring the intimate Education utopia. So, the reflection upon multiple platforms of projection of sights and perceptions of students and teachers is decisive for the productive affectations on the active participation on the human theater, both in their micro and macro social performances. Contemplating the curricula with some different cultural collections in complicity with the offer and appreciation of productions hidden by the hegemonic taste selection is decisive for the successful democratic formation - the intimate Education utopia. We here show our theoretical adventure that, involving the possible greatest diversity of cultural, imagistic and aesthetic flows, intends to contribute for a curricular accomplishment compatible with the present moment.

\section{The Intimate Education Utopia: Genealogy}

At a crucial moment of human organization it was necessary, at a specific and delimited space, to create the city on the western model and, consequently, idealize and make its govern and maintenance effective. So, it was necessary to create a specific formation system, already mentioned, that would face the offer of ideas and knowledge, as well as of many other symbolic and procedure accomplishments of meanings and other collective values: different types of knowledge which are necessary for comprehension and leading of town collectives, in other words, the so called civic education that was assigned to school. On the other hand, Education would soon be in evidence as a complex collective accomplishment constantly challenged, since it faces the living and transmuting body of the city. It is an indispensible impossibility full of sense that will always make education focus the defense and maintenance of what has been called public as well as all kinds of human productions. So, a non fully accomplished project gets into the 'all-city' with its indestructible legacy, its repercussion along different times that score the world, its intimate utopia that makes societies aware of their major and maybe only risk: their fragmentation, indicted by the speedy replacement of facts that work as a societal cementation by capitalized images which are surprising tools of a voracious market that threatens and transforms the city itself. 
So, the utopian energy of Education seems to point out the specific territories of interaction, accomplishment and aesthetic reframes of the world and social relations. The territory is ferociously crossed by all sorts of images, among which we have the visual ones, main focus of this research, as we project our reflection from the curricular field that should first occupy itself with the episteme of visual image, in other words, the curricular area of 'visual arts' teaching.

The integrity of the truths wrecks on the spasms of the agony of modernity and, among them, Education is reached by all sorts of questions. Its original conception contrasts with contemporary social conformations. Teach everything to everyone, civilize, prepare for the future or for stable work turn into dingy images. So, Education bears all kinds of contrasts on its tissues and in its fragmented organs. Since it becomes affected, the curricular structure has been cried for help in all sorts of methodological artifacts and in the so called transdisciplinary or utopian multicultural actions, having these movements, however, reached little or none success when radically facing the conveyed and, in a certain way, structuring truths of disciplinary scenery.

Questioning the concrete operation of what is taught, of the productive school results face of pedagogical leading ever adopted, it seems to be avoided in benefit of preservation of the intimate Education utopia. Repeatedly, the problems of Education are reduced to a methodological dimension, so we have avoided to confront the philosophical perspective that demands the reconsideration of the Education meanings and interpret evidences that the present time shows, most of them inside the different visual images and, especially, the way schools create the sight and valid their images and the images that cross themselves. In terms of Visual Arts, the truths that have led us so far reflect, and still represent, the belief in a specific objective way for teaching, inseparable from the idea that such way would be compatible to formal Education as a whole. If Education is shown as undoubtedly unstable by all sorts of questioning and for its own failure as a modern idealization conceived in a unique pattern to act on difference, it is, so, correct to state that Visual Arts teaching flows along disquieting seas. As it is known, the Visual Arts have always been associated and referenced, especially in terms of civilizing Education, to 'high culture', to specific uses of sensibility, to aesthetic sanitation, elements of a very specific visuality policy. Interplay of forces that have been pauperized as the validity of interchanges between aesthetic fruition and creation progress, irreversibly, beyond the territories of the granted art. Inseparable from the inevitable recognition of the diversity of cultures that cross the social nerve, we can see the consideration of the same diversity of sources and aesthetic products that arise from the cultural flows that have been in evidence.

Inside the granted system of art, the present pieces result from practices and appeal to materials, procedures, supports and surprising means which are in enormous tune with quotidian doings and knowledge. At the same time, the common subjects, those who do not intend to be artists, thanks to availability and easy access to sophisticated technology, show themselves as craftsmen and 
masters of visual arts. Harassed by all sorts of visual productions, we are also crossed by cultural senses evidenced on movements of these imagistic passages and, under these forces, we produce our personal images with records of what we want to keep as our memory and visual reference, maybe in the same intensity the first authors of the visual images history wanted to do it.

Although curricula still represent a melancholic esteem to specific edited side views from a past that has been fallen away, it is up to Visual Arts, on the curricular logic of Education, the responsibility of leading the game of contemporary visualities - a practice that is only possible, however, if in evident collision with discourses that support the glory of an official and limited past of visual images managed by the arts system. Indeed, the universe of contemporary visual aesthetics of Arts or streets seems to be more challenging, meaningful and eloquent than the museum collections and the theories and histories that summarize them. Image, aesthetic and visual culture composes a net that transcends any arts teaching program resultant from the modern Education project. Accomplishing the present Education and pulsating in it a sense for visual arts implies in accepting the intimate utopia that the first one slides among innovations and concerns of the second one, what implies in considering that new beauties, other fruitions and their epistemes drop sensually between the utilizable and the disposable images we find, take and not always understand. Images that threaten give consistency and also forge the view about present time. Visualities with a degree of complexity that shows sensibilities are not conductive through models Christianized by aesthetic pedagogies and that the background, without a human touch, where we try to create vital senses, suggest possibilities on the opposite flow of rational order of beauty and echo senses, it is convenient yet to reinforce, lamentably, beyond the limits of the digestion of bourgeois moral patterns.

This point of reflection that we propose reaches, so, the conceptual territory of a visuality policy that acts, especially, on location and uses of hegemonic art the way it is defended and recognized. Such policy presents itself on the most acute shape facing the emergency of a visual culture pedagogy that emerges as an opportune and daring resource when confronting the previously discussed panorama. We consider, so, that recovering some outstanding characteristics on the successful curricular conduction and approach throughout History of Education imposes itself on the movement of defending what should be important and necessary to develop on Arts teaching, once it is relevant to widely consider the aspects that shapes the Visual Arts as a discipline in order to evaluate the action of the hypothesized visuality policy and its effects upon concepts of 'imagistic world' and the categorical exiles where images are sent. 


\section{World Images and Imagistic World: Curriculum, Visual Culture and Teacher Formation}

The imagistic world is active as well as little elucidated and we reinforce that it performs an important role on quotidian life inside or outside schools. Yet, it severely interferes on the effectiveness of locations and practices of present society.

So, we consider important to consider some significant movements that result from the visuality policy and then unravel its participation on the preparation of the 'city-all'. During a quick evaluation we face its determinant traces: imposition of pieces, knowledge and doings invisibility in line with the visual detach given to cultural products hegemonic privileged or interesting for the market. It is an old practice still supported in some curricular conceptions that despite its reissues and innovations on public policies haven't moved from the aesthetic illuminist hierarchy. In this effort we change the investigative questioning to the concreteness of pedagogical accomplishments on Arts teaching and, in this products, the valued aspects and the ones which are left of put in second place with the intention of reflecting upon these orders as well as going deeper on the effort of understanding the political plots of visualities operating with movements that approach and move away from contemporary education on 'city-all' realities in order to contribute, in a certain way, with a progressive and emancipator Visual Arts field of shocks. A scenery that emphasizes a general aesthetic that, as desired by Onfray $(1997,224)$, is a condition necessary to preservation of differences and impediment to destruction wars based on aesthetic elections and its nets of political and theoretical sustention.

We understand that the studies of pedagogical actions on the visual culture field as well as of its results or productions cannot be restrained to school, curriculum or investigated practices. Although this work starts on school quotidian, its practices, challenges and other situations that arise from tensions between pedagogical traditions and present flows of visual culture, this investigative adventure implies, sooner or later, with more or less intensity, on the debate of prospective teacher formation in visual arts - what we truly want to contribute. We think that the return to school daily practiced through its cultural complexity is a fast and safe way that leads to elucidation of compromises and commitment of the visuality policy agents that define their paths and rhythms there. As we have already stated, definitions and routings that privilege some perspectives in the quotidian interaction with the cultural diversity common to most schools, light up some images and value specific ways of seeing and producing images, at the same time they disqualify procedures, exclude choices and release other images - these ones placed in the shade of the others. The recognition of these tensions is necessary for reaching possible advances on understanding de dynamics of moving maps and desire shocks that peps the political game in the visual city. It is in this face of the 'city-all' that the evaluation of 'visual culture', being energy of happening or 
field of study, will favor the conquest of useful elements for a restore process of teacher formation in Visual Arts.

Locus that explains much more about teacher formations than any analysis of curricular conceptions at College, the school where the Arts teacher work is the most eloquent and meaningful source of information for his/her formation. In other terms, the operations with images in the classrooms - constituted by the parties adopted by teachers when leading the dialogues with images; the selection of images that take part in the classes; the openness to the polyphonies of the visual object or the closure for this or that image in a monologic condition - emphasize the accomplishment of the visuality policy and its action in various dimensions and instances of visual arts teaching, a policy dedicated to reinforce specific values on different social instances and their confirmations in universities and other institutions that legitimate aesthetic, artistic and epistemic values. Any investigation about the use and production of images in the school quotidian offers, from this perspective, valuable contributions for curricular improvement on Arts teaching formation, especially if the desired formation is thought in tune with emancipator flows that call the effective practice of the visual art pedagogy that allows, without disqualifying Art and its system, the exploitation of knowledge and meanings of the universe of visual images beyond the curricular limits still in course in most part of Visual Arts teaching courses. Courses where it is common to occur the radical appreciation of images ratified by 'high culture', its system and procedures that occupy from the center to the borders of what should be known in terms of visual images.

On the other hand, the knowledge acquired by teachers while their still being graduate students, the official contents they are told to mediate and consequently their pedagogical practices are influenced by different points that end up emphasizing their practices inside the schools. Personal values arising from subjective nets and each one's cultural belongings dispute the construction of appreciations, reductions and comprehensions of disciplinary contents. Yet they participate actively on the reorganization of academically apprehended knowledge. So, elections, identifications, affinities and aesthetic desires, as well as incorporations and theoretical supports which are at stake on professional practice result on tensions between the different fields that form us, university, sociocultural means and other knowledge interchange dimensions. This net that composes teacher formation is also crossed by energies from the most dominant values in society. We emphasize that, in the university, questions about the conceptual and theoretical absolutism about aesthetic elections that constitute the Arts system have rare and limited space resulting, consequently, on a consolidated truth of Visual Arts granted as values to be accepted and incorporated as a legitimate content, just like the pedagogical practices during the teachers' formation will also be potentiated in attention to the necessary maintenance of the operative curriculum that focus the pieces and collections selected by the official history of Art as what is worth been discussed in terms of visuality. 
Arising from this curricular regimentation that refrains from wider investments in terms of visuality, most Visual Arts teachers do not consider the reading of images that are created and float outside the exclusive territory of Arts as content of their specific subject. This way, the movement of reading visual images rarely happens as a permanent act of editing what is seen as an authorial, therefore, political act. Little importance is given to the elucidation of strength of visual images, to the different ways they are seen, like their authors and articulators crave them to be apprehended. The same lack of attention happens in terms of the nets of contextual conditions in which they are created, consumed, preserved or discarded. Such panorama reveals that the opening and emphasis accomplished by the traditional cultures from the outskirts still do not prevent them from the disregard their aesthetic productions, visual elections and ways of seeing are exposed to, despite the social strength of cultural nets which are co-authors of many images that compose the quotidian visuality of the cities. It si, so, on the streets, markets and virtual nets, in other words, on the vibrating body of the 'city-all' that the most important images that interest students are designed, as well as the images that focus them. It is a crucial consideration for Visual Arts teaching at schools, after all, we know that not all students will become professionals of the Arts system, but all of them face and will face torrents of images more and more voluminous and cunning. It is necessary, in order to favor a really emancipator educational process, the preparation of these students for facing the visual traps set by the market that get stronger and more sophisticated in its seduction resources as well as more cruel in its predatory voluptuousness.

Along the History of Arts teaching in Brazil, different curricular parties have become official and have been practiced. In some aspects they have distanced themselves; in others they have become remarkably closed. However, in opposition to the value of Arts attributed by the privileged classes, the act of teaching this subject in public schools has been historically received low priority. The same has happened to its educational potentials. We understand that many and indispensable potentials have been severely wasted, what has helped to characterize Arts teaching with all sorts of reductions in relation to other subjects. A low intensity Arts teaching for the city centrifuged population which we assume to be supposedly exiled from the 'city-all'. In terms of imagistic references, as we have exposed, it is taught a type of Arts to be respected, not questioned as a cultural stuff and, especially, as something that depends on knowledge and behavior distant from the means and value of the cultures that cross and floats the schools - either the students' or the teachers'. Museums and other cultural equipments of the city, for example, are, at most, presented and known under an unquestionable certainty of their validity to everyone. It is as if here, Arts teaching would exclusively perform the role of subservience to its diagram in the city, where the official culture institutions should be respected and kept by everybody but enjoyed by few people - exactly those whose images, values and choices are reflected on the images of the collections in these institutions. Arising from the unconditional incorporation of the dominant cultures' values inside the curricular spaces, the 
constitution of public collections is accepted as well as the creation and maintenance of institutions that protect and promote them independent of the identification of consistent cultural ties among those who see and the images that are seen.

The fragility that surrounds the teaching formation in Arts is evident inside the curricular plots where we can see values related to the permanent reissue of truths of good and beauty, certainly disguised by updated emancipator vocabulary, skilled strategy of hiding old capitalism machinery interests and their allied beneficiaries. Active placement and survival in tune with the healthy extension of the vital flow are, today, the greatest collective challenges imposed by the 'city-all'. Severe political determinations require confrontations to be articulated in formal education, from which we have detached some conditions and pointed some elements of teacher formation that contribute for the present position of Arts teaching - so close and so distant from visual culture at the same time.

Unfortunately, it is still recurrent the idea of an aesthetic learning - as if the aesthetic experience could be colonized by methodologies and didacticism of Arts teaching - as well as it is rarely assumed inside the visual arts curricula - at college in terms of basic education. Through the visual culture pedagogy it is possible to understand the present plots of visuality policy. We reiterate that the college formation, in most visual arts formation courses, seems to avoid the opportunities and investments on intellectual adventures that question the validity of principles and traditional postulates in terms of visual images making things difficult, for future teachers, to live the conceptual displacements necessary for distension of truths of Arts and other institutional constructions that end up sanitizing and atrophying knowledge and the productive exploitation of imagistic and aesthetic universes of the city in its wide diversity.

The Arts teacher's updated formation needs curricular enlargement that allows to consider that Arts teaching in contemporary education can be reduced neither to aestheticization of politics nor to politicization of Arts but, as Onfray (2001) aspires, to formulation and practice of a general aesthetic in opposition to the private aesthetic, submitted to separated imperatives and frequently put as auxiliary of the dominant power. Such 'general aesthetic' aims at passing the oppositions between art and life, street and museum, not to create, as often happens, new references and criteria from life and street, but to call up art and museum in an upward dynamic of democrat and productive relationship with the aesthetics that float in all instances and frequencies of the 'city world'.

The Arts teaching school subjects pointed in many studies as victims of curricular order and its institutional supports tools have a double strength that must be thought. The first one is their mild, but effective, strength of ratification of truths and values enunciation and recurrent in pedagogical practices from other curricular areas: value which are still dominant inside the Brazilian social plot, like moral, sexist hygienic, heterostandardization, cultural segregation etc. that contaminate the epistemic order and creation as well as other investments on knowledge. The second one is the contribution that 
experience, dealing and aesthetic production provide to subjects formation, always tensioned by the first aspects which were cited. We also refer to almost national heritages like the still immanent slavery, euroreferencing, phallocracy and Christianity that represent the most violent influences upon visuality policies acting on official and quotidian official visual arts teaching.

The aspects here summarized argue in favor of a visual arts teaching involved with a wide political shock in which the visual world is detached. This way we intend to favor a pedagogical routing that reconsider the borders of cultural and imagistic territories enlarging the positive, well known and recognized aspects of the subject: playfulness, individual and collective involvement and pleasure, creativity and poetic expression, especially freedom from the school severity. In other words, we postulate, in simultaneous movements two deployments on Arts teaching: the elucidation of meanings and values of Arts that prevail on globalizing flows and their roles along history. This means careful and specific conceptual investment involving philosophical, historical and cultural dimensions. Equally important, another deployment would be an attentive exploitation of procedural aspects on Arts teaching: the pedagogical redirection of elaboration and investigative exploitation of production and interaction with images beyond the instituted limits kept in line with Arts system, its ideological boundaries and visual shields.

So, we suggest a pedagogical poetics that overcome the entropy that results from the time flow that faces the school inadequacies and the adoption of procedures that result in effective gains for the educational process without resulting on the resumption of a merely content, obvious and anachronistic practice. We understand that the participation of Arts teaching on a successful school formation in tune with present time depends on the acute conceptual limits imposed to the first one and to the recognition of overflows that its epistemic field and peculiar practices have imposed to curricular gates of the second one: the contemporary formal education.

\section{Some Considerations to Round off this Presentation...}

...about art teaching on basic education, its lack of boundaries and overflows. More than making art, we make images from the act of imagining and we appeal to them when editing our quotidians.

We interrupt this brief study about some aspects of the world of visuality and imagistic at school by underlining that the investigation of the 'image' and of the act of 'see' (as aesthetic and cultural potentiality) should become, at first and last moment, in charge of the subject called 'art teaching'. Inside this still disciplined area, in terms of arts or beyond its borders, we have a privileged opportunity of evaluation and investment on relations among the images boys and girls -children or teenagers - create, pep from their individualities and collectives, their affections and antagonisms of the continuous work of being part and interacting with the world. This work configures a net of imagistic elaborations in which we detach the formulation of images privileged by 
teachers and students. Since we understand that such formulations guide the school vitality, we alert for the importance of elucidating them, depending on the paving and on the deflagration of initiatives both on conceptual dimension and on reorganization of quotidian practices. Coping, besides taking advantage of school daily production, will improve the reframe of teacher and student's characterization, indispensable condition for matching school and present time. Present time which has left behind the faith on fixed methodologies and that evokes and calls up the collective creation. Present time that questions the individual possession of any human piece or of any other thing that represents exclusive use and trade. Present time that recreates childhood and youth and creates new body shapes and languages of children and young people. It also requires from them an unpublished creation on the 'poemaction' of inventing life that results on the inseparable invention of freedom on school environment apart from the pedagogy of coercion and more intense on the condition of shelter in which considering the strength of visual images and increasing the ways of learning them is indispensable.

We could not reduce the present moment, in any approach, to a single characteristic. If we could consider it as the image era, we could also defend it as the time of doubts and of transfigurations, time of movements and of tribes. The radical time of iconoclasm, what does not mean, however, the destroyed neglecting face of certainty and truths of the past - what now seems to be naive. The time of tribes (Maffesoli, 2006) is also the time of invention of collective possibilities shaped by individual accomplishments, life of aesthetic doings, life as tattoo of difference that requires to be considered, interpreted and brought to fruition, since anyone's early ages, in all visualities that cross all cultural flows in the cities that live the 'city-all'.

The present time is also the time of imagistic games that require our expectations and private truths to enlarge in order to flow better and to make better use of the other's events, as well as answer to the aesthetic instigations of the non-identical. The sensual power of difference, in the field of ideas, arts or quotidian insignificancies, makes life, 'the' life. And the school events provide the connection among students and teachers, children and children, youngsters and youngsters, young people and adults, among incarnate images and imagistic and imagined bodies.

So, we detach the role of games of affections, sensibilities, creations and aesthetic choices as relevant elements to be added to other aspects detached as important on modernization of visual arts teaching. The aspects which seems to be technical cannot unstuck from political questions discussed in terms of visuality. It cannot discharge the articulation with production and interaction of concepts necessary to analysis and (re)creation of schools sceneries either, otherwise, the risk of getting the school update disappointed will increase as well as its consequent fortification before the present challenges.

The game of potentialities of difference and its territorialization is considered immanence of contemporaneity. And in the scope of visual arts and its determinant action at present time, neither those who see nor those who are seen escape from the challenges. The construction of the sight becomes 
important and significant due to the images empire. Seeing and creating images involve corporeity and symbolic ambiences that constitute the same action. The comprehension of these tensions allows us to elucidate the processes that lead both to visibility and to deletion of objects and subjects and of what can be deleted and detached from one in the other.

We bet the reconfiguration of curricular plots in the field of visual arts is fundamental for the coping of rational order of ideas and truths still present in a great part of formal education. Ordination that shows clefts in which it is pronounced the evident and eloquent uncontrolled situation of what has been judged and of what has been controlled during school formation, what, beyond undeniable important accomplishments, has still privileged coercion and annihilation. Annihilation of presences, visualities and perspectives severely imposed by the edition of views and blindness epistemology that moves away everything that the policies of faith in school, strong reverberation of society, is discharged because they cannot understand, judge as hasty nefarious or simply for not seeing it.

We conclude these records by recovering some aspects that have been considered important by concerns and actions that favor visual arts teaching in tune with the needs of the 'city-all' which is also the imagistic city. In other words, the search for resources that make easy the access and proximity with images from various cultural origins; the promotion and approximation of images and the so called popular culture aesthetics accomplishments; the extension of resources that make the interchange of information (necessary for visual assimilation of quotidian images - both the most familiar and the most distant ones) easy; promote visitations to collections, different patrimonies and cultural events; the mediator action of knowledge about Art and its production about aesthetics and visualities, both connected to great tradition and the recent discourses that question them, reinterpret prejudices, stereotypes and reframe the outskirts aesthetics; the reduction of embarrassments that make fruition and other uses of the city's cultural offers hard; face the images and invest in hermeneutic extensions that disentangle from anachronistic interpretative bias and especially when meeting the demands of changes on epistemic relations with images and their cultural contexts. So, we understand Visual Culture as a new and innovator field of knowledge with an inevitable exploitation by present Education. Maybe as a perspective, as notion, more than as theory and methodology which are protected inside its own truth regimen, we think Visual Culture as an epistemological tune in the same frequency as the 'city-all', in other words, on the wide and deep make of comprehension and apprehension of the 'city-image' as a heterogeneous and collective piece, which is also the desiring city in terms of humanity in free and wide vital flow.

\section{References}

Baudrillard, Jean. A dupla exterminação. In: Tela total: mito-ironias da era virtual e da imagem. Porto Alegre: Sulina, 1997. 
Bauman, Zygmunt. Capitalismo parasitário. Rio de Janeiro: Jorge Zahar Ed., 2010.

Berger, John. Modos de ver. Lisboa: Edições 70/ Martins Fontes, 1982.

Bronowski, Jacob. A escalada do homem. São Paulo, SP: Martins Fontes, 1992.

Canclini, Nestor G. Consumidores e cidadãos: conflitos multiculturais da globalização. Rio de Janeiro: Editora UFRJ, 1995.

Canevacci, Massimo. Culturas extremas: mutações juvenis nos corpos das metrópoles. Rio de Janeiro: DP\&A, 2005.

Certeau, Michel de. A invenção do cotidiano: 1. Artes do fazer. Petrópolis, RJ: Vozes, 1994.

Dias, Souza. Questão de estilo: arte e filosofia. Coimbra: Pé de página, 2004.

Hernandez, Fernando. Cultura Visual, mudança educativa e projeto de trabalho. Porto Alegre: Artes Médicas Sul, 2000.

. Catadores da Cultura Visual: uma proposta para uma nova narrativa educacional. Editora Mediação, Porto Alegre: 2007

Maffesoli, Michel. A contemplação do mundo. Porto Alegre: Artes e Ofícios, 1995.

. No fundo das aparências. Petrópolis, RJ: Ed. Vozes, 1999.

. A parte do diabo. Rio de Janeiro: Record, 2004.

O tempo das tribos: declínio do individualismo nas sociedades de massa. São Paulo: Forense universitária, 2006.

. A sombra de Dionísio: contribuição a uma sociologia da orgia. São Paulo: Zouk,

Mumford, Lewis. A cidade na história: suas origens, transformações e perspectivas. São Paulo, SP: Martins Fontes, 2001.

Oliveira, Inês Barbosa de. Currículos praticados. Rio de Janeiro: DP\&A, 2003.

Oliveira, Marilda Oliveira de.(Org.). Arte, Educação e Cultura. Santa Maria, RS: Editora da UFSM, 2007.

Silva, Tomaz T. O currículo como fetiche: a poética e a política do texto curricular. Belo

Horizonte. Autentica: 1999.

Onfray, Michel. A política do rebelde: tratado de resistência e insubmissão. Rio de Janeiro: Rocco, 2001.

A potência de existir: manifesto hedonista. São Paulo, SP: Martins Fontes, 2010.

Simon, Roger I. A pedagogia como uma tecnologia cultural. In: Silva, Tomaz. Alienígenas em sala de aula: uma introdução aos estudos culturais na educação. Petrópolis, RJ: Vozes, 1995.

Tourinho, Irene e Martins, Raimundo (Orgs.) Educação da Cultura Visual: narrativas de ensino e pesquisa. Santa Maria, RS: Editora da UFSM, 2009.

Wulf, Christophe. Antropologia da Educação. Campinas: Alínea, 2004.

Zabala, Antoni. A prática educativa: como ensinar. Porto Alegre: Editora Artes Médicas Sul Ltda., 1998. 
